Daniel G. Ezra

Michelle P. Y. Chan

Lola Solebo

Aeesha N. J. Malik

Elizabeth Crane

Andrew Coombes

Marie Healy

\section{Randomised trial comparing ocular lubricants and polyacrylamide hydrogel dressings in the prevention of exposure keratopathy in the critically ill}

Published online: 12 November 2008

(C) Springer-Verlag 2008

The online version of the original article can be found under doi:10.1007/s00134-008-1284-4.

\section{G. Ezra (৫)}

Moorfields Eye Hospital, London EC1V 2PD, UK

e-mail: d.ezra@ucl.ac.uk

Tel.: +44-7815-732455

Fax: $+44-20-82025383$

M. P. Y. Chan - L. Solebo - A. N. J. Malik - A. Coombes Department of Ophthalmology, Royal London Hospital,

London E1 1BB, UK

E. Crane

Centre for Environmental and Preventive Medicine,

Wolfson Institute of Preventive Medicine,

Queen Mary School of Medicine and Dentistry,

London EC1M 6BQ, UK

M. Healy

Department of Intensive Care, Royal London Hospital,

London E1 1BB, UK
Erratum to: Intensive Care Med

DOI 10.1007/s00134-008-1284-4

The conflict of interest statement for Dr. Ezra was inadvertently deleted in production.

It is reproduced here:

Conflict of interest statement Daniel Ezra received a $£ 400$ travel grant from Geistlich (manufacturers of Geliperm) in 2006 to attend the ESICM meeting in Barcelona.

Moreover, Dr. Malik's initials were given incorrectly. Her correct name is Aeesha N. J. Malik. 